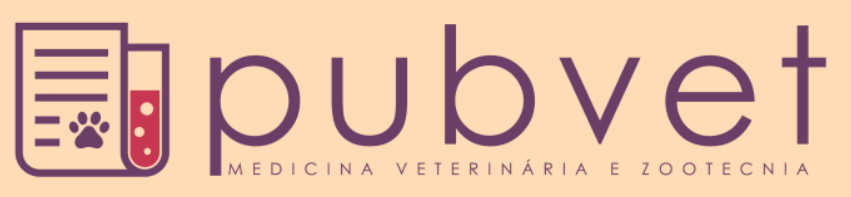

https://doi.org/10.22256/pubvet.v12n2a28.1-9

\title{
Potencial da ensilagem de capim-braquiaria com inclusão de farelo de arroz: Revisão
}

\author{
Bruno Rafael Santos Borges ${ }^{\bullet} 1^{*}$, Fagton de Mattos Negrão ${ }^{\bullet}$, Anderson de Moura \\ Zanine ${ }^{\bullet}$, Alayzza Machado ${ }^{1}$, Flávio Henrique Bravim Caldeira ${ }^{\ominus 2}$, Túlio Otávio \\ Jardim D'Almeida Lins 2
}

${ }^{I}$ Discente do curso de Engenharia Agronômica, Instituto Federal de Rondônia, Colorado do Oeste-RO, Brasil.

${ }^{2}$ Professor EBTT - Departamento de Zootecnia, Instituto Federal de Rondônia, Colorado do Oeste-RO, Brasil. E-mail: fagton.negrao@ifro.edu.br; flavio.caldeira@ifro.edu.br; tulio.jardim@ifro.edu.br

${ }^{3}$ Departmento de Zootecnia, Universidade Federal do Maranhão, Chapadinha-MA, Brasil. E-mail: anderson.zanine@ibest.com.br Autor para correspondência, E-mail: brunoborges0615@gmail.com

\begin{abstract}
RESUMO. O Brasil é um dos países de maior potencial de produção pecuária, determinado principalmente pelas suas condições climáticas, vasta extensão territorial e plantas forrageiras, que constituem a base da dieta dos ruminantes na grande maioria dos sistemas de produção existentes no país. Nessa premissa, uma das alternativas para solucionar a falta de alimento durante o período do ano é a conservação do excedente da produção de capim na forma de silagens. Todavia, o elevado teor de umidade no momento da ensilagem predispõe o crescimento de microrganismos indesejáveis, que resultam em perdas por gases e efluentes. Entretanto, uma das formas de reduzir essas perdas é a adição de coproduto com alto poder higroscópico e que aumente o valor nutricional e beneficie a fermentação durante o processo de conservação da forrageira. Desenvolveu-se o presente estudo com o objetivo de avaliar o perfil fermentativo, as perdas por gases e efluente, recuperação de nutrientes, o valor nutritivo, a degradabilidade ruminal in situ e o fracionamento de carboidratos e proteína das silagens de capim contendo aditivo higroscópico, como o farelo de arroz.
\end{abstract}

Palavras chave: Conservação de forragem, coproduto, valor nutricional

\section{Potential of ensiling braquiaria grass with inclusion of rice meal: Review}

ABSTRACT. Brazil is one of the countries with the highest potential for livestock production, mainly determined by its climatic conditions, vast territory and forage, that are the basis of the diet of ruminants in most production systems in the country. This assumption, an alternative to solve the lack of food during the year is the conservation of surplus grass as silage. However, the high moisture content at the ensilage predispose the growth of undesirable microorganisms, which result in loss of gases and effluents. However, one of the ways to reduce these losses is the addition of coproduct with high hygroscopic and increase the nutritional value and benefits during the fermentation process of preserving forage. Developed this study aiming to evaluate the fermentation characteristics, gas losses and effluent, nutrient recovery, nutritive value, the in situ degradability and fractionation of carbohydrates and protein in silages added hygroscopic additive, as rice meal.

Keywords: Forage conservation, coproduct, nutritional value 


\title{
Potencial del ensilado de pasto-braquiaria con inclusión de salvado de arroz: Revisión
}

\begin{abstract}
RESUMEN. Brasil es uno de los países con mayor potencial para la producción ganadera, determinado principalmente por su clima, vasta extensión territorial y plantas forrajeras, que constituyen la base de la alimentación de los rumiantes en la mayoría de los sistemas de producción existentes en el país. En esa premisa, una alternativa para resolver la falta de alimentos durante el período del año es la conservación de los excedentes de la producción de pasto en forma de ensilaje. Sin embargo, la humedad alta en el momento de ensilado predispone el crecimiento de microorganismos indeseables, que se traduce en pérdidas por gases y efluentes. Sin embargo, una manera de reducir estas pérdidas es la adición de coproducto con alto poder higroscópico y que aumente el valor nutricional y beneficie la fermentación durante el proceso de conservación de la forrajera. Se llevó a cabo este estudio con el fin de evaluar el perfil de fermentación, las pérdidas por gases y efluente, recuperación de nutrientes, el valor nutritivo, la degradabilidad ruminal in situ y el fraccionamiento de los carbohidratos y proteínas de ensilados de pasto que contienen aditivo higroscópico, tales como salvado de arroz.
\end{abstract}

Palabras clave: Coproducto, conservación de forraje, valor nutricional

\section{Introdução}

Apesar da alta produção de matéria seca das plantas forrageiras, essas apresentam sua produção concentrada nos meses em que existem elevada temperatura e umidade do ar, exigindo a adoção de técnicas que visem solucionar, ou pelo menos amenizar a quantidade e qualidade do alimento ofertado no período seco. Uma alternativa para solucionar esse impasse é a conservação de forragem por meio da ensilagem.

Partindo dessa premissa, houve crescente interesse na ensilagem de gramíneas tropicais, pois apresentam elevada produção de matéria seca. Por conseguinte, o uso do excedente da produção de capins na forma de silagem tem que ser visto de forma técnica, pois, o elevado teor de umidade, alto poder tampão e a baixa concentração de carboidratos solúveis predispõem o crescimento de microrganismos indesejáveis, que resultam em perda de forragem e menor valor nutritivo.

Uma forma de reduzir as perdas de nutrientes na forma de gases é a adição de coproduto com alto poder higroscópico que aumente o valor nutricional e beneficie a fermentação durante o processo de conservação da forrageira, como, por exemplo, o farelo de trigo (Zanine et al., 2006a, Zanine et al., 2006b), a raspa de mandioca (Zanine et al., 2010), o farelo de arroz, a casca de soja e o fubá de milho (Monteiro et al., 2011).

O farelo de arroz é um coproduto com potencial de ser incluído no processo de ensilagem de capim, tanto por sua capacidade em reter água como por melhorar a composição química das silagens produzidas. Informações científicas acerca do uso do farelo de arroz na produção de silagens de capins são restritas, por isso, pesquisas com esse intuito contribuem para produção de alimentos alternativos na nutrição de ruminantes. Nesse sentido, o presente estudo teve o objetivo de avaliar o perfil fermentativo, as perdas por gases e efluente, recuperação de nutrientes, o valor nutritivo, a degradabilidade ruminal in situ e o fracionamento de carboidratos e proteína das silagens de capim-braquiaria aditivada com farelo de arroz.

\section{Potencial da ensilagem de gramíneas perenes}

O Brasil é um dos países de maior potencial de produção pecuária, determinado principalmente pelas suas condições climáticas, vasta extensão territorial e plantas forrageiras, que constituem a base da dieta dos ruminantes na grande maioria dos sistemas de produção existentes no país. Dentre as espécies forrageiras elegíveis para produção de silagem, as gramíneas do gênero Brachiaria têm sido muito utilizadas devido ao seu elevado potencial de produção de biomassa, boa adaptabilidade, facilidade de estabelecimento, persistência, além de serem resistentes às doenças (Souza Filho \& Dutra, 1991). A adubação nitrogenada é fundamental para o aumento da produção de biomassa, pois o aumento do teor de nitrogênio no solo é uma das formas de incrementar a produtividade, principalmente quando a forrageira responde à aplicação desse nutriente (Martuscello et al., 2005). 
Nesse sentido, Fagundes et al. (2005) avaliaram o acúmulo de forragem em pastos de Brachiaria decumbens adubados com nitrogênio $(75,150,225$ e $300 \mathrm{~kg} / \mathrm{ha})$ e submetidos a uma mesma intensidade de pastejo. O capim-braquiária apresentou incremento de produção de matéria seca proporcional às doses de nitrogênio. Observaram-se maiores valores de taxa de acúmulo de folha, colmo e forragem nas estações primavera-verão e valores menores no inverno. Os autores concluíram que as variações nas condições climáticas com as estações do ano alteraram as taxas de acúmulo de folha e colmo, senescência e de produção de forragem.

De acordo com Souza (2002) o gênero Brachiaria são forragens tropicais com produções de 10 a 18 toneladas de $\mathrm{MS} / \mathrm{ha}^{-1} / \mathrm{ano}^{-1}$. Euclides et al. (2001) ao estudarem os cultivares marandu, xaraés e piatã, constataram massa de forragem média no pré-pastejo de $4.075,3.850$ e 3.730 $\mathrm{kg} / \mathrm{ha}$ de matéria seca, respectivamente. Chiarelli et al. (2009) comparando os capins marandu, piatã e xaraés consorciado com milho, não encontraram diferenças para a produção de matéria seca e a porcentagem de espigas do milho entre as três cultivares avaliadas $(4.921,6.400$ e $5.837 \mathrm{~kg} / \mathrm{ha}$, respectivamente).

Nesse contexto, a conservação da produção de forragem como alternativa para suprir as exigências nutricionais e manter o desempenho animal constante durante todo o ano é uma realidade nacional e, sua viabilidade pode ser conseguida por meio da conservação de forragem oriunda da maior produção no período chuvoso.

\section{Limitações para ensilagem de capins tropicais}

A ensilagem de capins colhidos no estádio de maturidade em que é elevado o valor nutritivo, ou seja, mais jovens, favorece o desenvolvimento de microrganismos deterioradores, principalmente bactérias clostrídicas e enterobactérias que produzem nitrogênio amoniacal e principalmente ácido butírico devido à alta umidade (acima de $70 \%$ ), elevado poder tamponante e baixo teor de carboidratos solúveis (menor que $5 \%$, com base na MS) (Zanine et al., 2006a). McDonald (1981) destacaram que, concomitantemente à formação de ácido butírico, ocorre degradação de proteína e do ácido lático, explicando, dessa forma, os menores teores de proteína bruta na silagem sem aditivo, ou seja, silagens com alta umidade.

A conservação de forragens na forma de silagem é dependente da quantidade de açúcares prontamente fermentáveis presentes na planta a ser ensilada. Se a concentração de carboidratos solúveis (CS) é adequada, as condições são mais favoráveis para o estabelecimento e crescimento de bactérias do gênero Lactobacillus, as quais produzem o ácido lático, que apresenta maior potencial de acidificação em relação aos outros ácidos orgânicos produzidos no processo de ensilagem, é desejado para proporcionar uma rápida estabilização do $\mathrm{pH}$ e melhor conservação do material ensilado (McDonald, 1981).

As alterações decorrentes do processo fermentativo nas silagens são resultantes da fermentação em condições de anaerobiose. As bactérias ácido-láticas epífitas fermentam os carboidratos solúveis das plantas, gerando ácido lático e acético, reduzindo o pH e inibindo a ação de microrganismos indesejáveis. Além de preservarem a silagem, os ácidos orgânicos são fontes de energia para o metabolismo dos ruminantes (McDonald, 1981).

Dos fatores que determinam o padrão de fermentação durante a ensilagem, aqueles relacionados com a planta forrageira estão representados pelo teor de matéria seca (20-25\%), adequado teor de carboidratos solúveis (8-15\%) e baixo poder tampão (<20 eq. mg HCl/100g MS), e aqueles relacionados ao meio, pois uma boa fermentação só é garantida em condições de anaerobiose, desde o ponto de colheita, tamanho de partículas, rápido enchimento do silo, compactação para efetiva expulsão do oxigênio do interior do material, até a perfeita vedação do silo a fim de evitar a infiltração de ar e/ou de água (Andrade \& Lavezzo, 1998).

Nesse sentido, tendo por base o ponto ideal entre quantidade e qualidade de colheita, a ensilagem de capim apresenta alguns entraves como os baixos teores de matéria seca, carboidratos solúveis e poder tampão, que dificulta o declínio do valor de $\mathrm{pH}$, culminando em silagem de menor qualidade. Situação que tecnicamente tem que ser compensada com a inclusão de aditivos específicos, como os coprodutos higroscópicos oriundos da agroindústria.

\section{Coprodutos da agroindústria na produção de silagem de capins tropicais}

Entre as soluções para inibir o crescimento dos microrganismos indesejáveis, entre eles o Clostridium, e minimizar as perdas por fermentação secundária da silagem de capim, está 
o uso de aditivo com altos níveis de matéria seca e capacidade de retenção de água e com boa aceitabilidade pelo animal. Devem ser, também, de fácil manipulação, baixo custo e fácil aquisição (Igarasi, 2002). Todavia, a adição de material absorvente (cereais moídos e coprodutos) é uma alternativa ao emurchecimento. Apresenta a vantagem de não exigir operações extras no recolhimento da forragem e de reduzir o risco de perdas por ocorrência de chuvas durante a desidratação, além de aumentar o aporte energético do alimento devido à redução da perda de carboidratos solúveis e respiração celular. Ferrari Junior et al. (2009) observaram que a adição de $12 \%$ de farelo de mandioca mostrou-se mais eficiente que o emurchecimento em aumentar o teor de matéria seca da silagem de capim-elefante.

Os aditivos mais frequentemente utilizados em silagens de capins tropicais são representados por coprodutos regionais das agroindústrias, principalmente, as de processamento de grãos de cereais. Nesse cenário, encontram-se relatos na literatura da utilização de fubá de milho, rolão de milho, farelo de trigo e farelo de mandioca (Andrade \& Lavezzo, 1998, Zanine et al., 2006a, Zanine et al., 2006b, Zanine et al., 2010), com o objetivo de promover melhoria nas condições de fermentação da silagem, principalmente pelo incremento do teor de matéria seca.

Zanine et al. (2006b) avaliaram a inclusão de $0,20,40$ e $60 \%$ de farelo de trigo sobre as perdas, recuperação da matéria seca e qualidade da silagem de capim-mombaça. A adição de farelo de trigo reduziu as perdas por gases e as perdas por efluentes. A recuperação da matéria seca foi menor para o tratamento sem farelo de trigo. Os valores de proteína bruta aumentaram e os valores de FDN e FDA na silagem reduziram de forma linear em função da aplicação de farelo de trigo. Os autores concluíram que a inclusão de $20 \%$ de farelo de trigo é suficiente para garantir melhorias na qualidade da silagem de capim-mambaça.

Andrade et al. (2010b) avaliaram a inclusão de $0,10,20$ e $30 \%$ de farelo de mandioca, casca de café ou farelo de cacau sobre as perdas por gases e efluente, as características fermentativas e o valor nutritivo de silagens de capim-elefante. A adição dos aditivos provocou aumento dos teores de matéria seca, e farelo de mandioca foi o aditivo mais eficiente no controle das perdas por efluente e gases. A adição de farelo de mandioca, casca de café e farelo de cacau garantiu altas taxas de recuperação de matéria seca, enquanto o farelo de mandioca e o farelo de cacau favoreceram a redução dos valores de $\mathrm{pH}$ e os teores de nitrogênio amoniacal, respectivamente, refletindo na melhoria do perfil de fermentação das silagens. Os autores concluíram que a adição de farelo de cacau ao capim-elefante no momento da ensilagem contribui para o aumento dos teores de nitrogênio total, porém aumenta os teores de nitrogênio insolúvel em detergente neutro e em detergente ácido.

A disponibilidade de coprodutos provenientes da agroindústria e a crescente preocupação com problemas ambientais têm gerado maior interesse quanto ao destino destes materiais, quanto ao possível aproveitamento na alimentação animal e até mesmo como material higoscópico na ensilagem de forragens com alto teor de umidade (Bernardino et al., 2005, Zanine et al., 2006a, Zanine et al., 2006b, Zanine et al., 2010). Por conseguinte, destaca-se que o farelo de arroz pode ser uma alternativa viável na produção de silagem de gramíneas perenes. Neste sentido, Monteiro et al. (2011) relataram que o farelo de arroz apresenta potencial para utilização na produção de silagem, por ser um coproduto da indústria de beneficiamento dos grãos de arroz, que, devido aos seus baixos teores de fibra em detergente neutro e alto teor de extrato etéreo, pode ser utilizada como aditivo, reduzindo as perdas durante o processo fermentativo das silagens.

Monteiro et al. (2011) avaliaram o padrão de fermentação e a composição bromatológica da silagem de capim-elefante utilizando como aditivo o farelo de arroz, a casca de soja, o fubá de milho, a cana-de-açúcar picada ou o inoculante bacteriano. Os aditivos promoveram adequado padrão de fermentação face aos valores de $\mathrm{pH}$ $(3,70$ a 3,96) e de nitrogênio amoniacal $(3,67$ a $4,44 \%$ do N-total) verificados na silagem. Os autores concluíram que o farelo de arroz proporcionou a obtenção de silagens com teores mais elevados de proteína bruta $(6,4 \%)$ e nutrientes digestíveis totais $(61,9 \%)$ em relação ao tratamento sem aditivo.

Vale destacar que o tipo de aditivo absorvente a ser utilizado na ensilagem dependerá das características do material a ser ensilado, da disponibilidade e custo do aditivo. Porém, fica evidente que quando o aditivo absorvente utilizado em quantidades adequadas é capaz de proporcionar aumento do teor de matéria seca do material ensilado, e promove ambiente menos 
favorável para o desenvolvimento de microrganismos deletérios, contribuindo de forma expressiva para a preservação e qualidade da silagem.

\section{Arroz e seus coprodutos}

Apesar de o arroz ter como maior importância à alimentação humana, a cultura gera vários coprodutos que podem ser utilizados na alimentação animal principalmente em épocas do ano quando ocorre escassez de outras fontes de alimentação, como a palha obtida após a colheita no campo; a casca como resíduo do beneficiamento; a quirera (arroz quebrado) obtida na peneiragem após a retirada da casca silícica e lignocelulósica do grão; o farelo de arroz integral (FAI) obtido do polimento do arroz contendo quantidade variável de amido, dependendo do grau de polimento e o farelo de arroz desengordurado (FAD) como resultado da extração de óleo para consumo humano que constitui $82 \%$ do peso do FAI (Andriguetto et al., 2003).

De acordo com os dados da Companhia Nacional de Abastecimento - CONAB, o arroz está entre os cereais mais consumidos do mundo. O Brasil é o nono maior produtor mundial e colheu 11,26 milhões de toneladas na safra 2009/2010. A produção está distribuída nos estados do Rio Grande do Sul, Santa Catarina e Mato Grosso (515,5 mil toneladas). O cultivo de arroz irrigado, praticado na região Sul do Brasil contribui, em média, com 54\% da produção nacional, sendo o Rio Grande do Sul o maior produtor brasileiro. Em Santa Catarina, o plantio por meio do sistema prégerminado responde pelo segundo lugar na produção do grão irrigado, com 800 mil toneladas anuais.

O grão de arroz é constituído da cariopse (fruto com uma semente presa ao pericarpo em toda a extensão) e de uma camada protetora, a casca que é formada por duas folhas modificadas, a pálea e a lema, corresponde a cerca de $20 \%$ do peso do grão. A cariopse é formada por diferentes camadas, sendo as mais externas o pericarpo, tegumento e camada de aleurona, que representam 5-8\% da massa do arroz integral. $\mathrm{O}$ embrião ou gérmen está localizado no lado ventral na base do grão, é rico em proteínas e lipídios, e representa 2-3\% do arroz integral. $\mathrm{O}$ endosperma forma a maior parte do grão (89-94\% do arroz integral) e consiste de células ricas em grânulos de amido e com alguns corpos proteicos (Andriguetto et al., 2003). No processo de beneficiamento do arroz a operação da descascagem, como o próprio nome diz, separa a casca da cariopse, obtendo-se o arroz integral. O grão descascado é polido para remoção do farelo (pericarpo, tegumento, camada de aleurona e gérmen), que representa 8,5 a $14,8 \%$ do arroz integral (Andriguetto et al., 2003) obtendo-se o arroz branco polido para alimentação humana, gerando o coproduto (farelo) que pode ser incluso na dieta de ruminantes.

\section{Fracionamento de carboidratos e proteína da silagem de capim-braquiaria com inclusão de coprodutos agroindustriais}

Dos nutrientes necessários às exigências nutricionais para mantença, crescimento e/ou produção de ruminantes, a energia resultante da degradação ruminal da parede celular é a principal contribuição dos volumosos. Durante a evolução da avaliação de alimentos para ruminantes, diversas técnicas in vitro, in situ e in vivo foram desenvolvidas com o intuito de melhor caracterizá-los, como, também, facilitar a predição do desempenho animal a partir de certas características dos alimentos fornecidos na dieta (Ítavo et al., 2002).

Os métodos para estudar a degradabilidade ruminal dos alimentos, apesar de serem utilizados há muitas décadas, nos últimos anos têm se desenvolvido consideravelmente. A técnica in situ destaca-se por permitir o contato do alimento teste com o ambiente ruminal, embora o alimento não esteja sujeito a todos os eventos digestivos, como mastigação, ruminação e passagem (Nocek, 1988). No entanto, Mertens (1993) relatou que esta técnica permite obter valores próximos aos obtidos in vivo.

A estimativa da degradação ruminal dos alimentos tem sido fundamental para avaliar a quantidade de nutrientes disponíveis para os microrganismos do rúmen e sua qualidade. A degradabilidade in situ baseia-se na colocação de pequena quantidade de um determinado alimento em bolsa porosa não degradável e sua subsequente inserção (ou incubação) no conteúdo ruminal de animais canulados no rúmen (Molina et al., 2003). Por isso, a técnica de degradabilidade in situ tem sido adotada para se determinar o desaparecimento de nutrientes no rúmen em função do tempo de incubação. Não existe, na literatura, consenso sobre o tempo de incubação ruminal que permita representar melhor a fração indigestível das amostras, observam-se períodos 
variáveis, 144 (Cabral et al., 2004) e 240 (Clipes et al., 2006). Como regra geral, para que o máximo potencial de degradação seja alcançado. Ørskov \& McDonald (1979) recomendam, para concentrados, de 12 a 36 horas de incubação; para forragens de alta qualidade, de 24 a 60 horas; e de 48 a 72 horas para forragens de baixa qualidade.

Sniffen et al. (1992) sugeriram que na avaliação dos alimentos, os teores de nitrogênio e de carboidratos sejam fracionados, possibilitando formular dietas que promovam perfeita sincronização entre a disponibilidade de carboidratos e nitrogênio no rúmen. Na mesma premissa Tonani et al. (2001) relatam que a determinação de frações degradáveis ou não no rúmen é de suma importância no balanceamento de rações para ruminantes. Sistemas mais modernos de dietas para ruminantes levam em consideração a cinética da degradação das diferentes frações dos alimentos, particularmente carboidratos não estruturais e proteína, além de estimar o potencial de crescimento microbiano a partir da fração fermentável.

Uma das formas de se obter a viabilidade de uso de um alimento é por meio da avaliação de suas frações proteicas. Cabral et al. (2000) reportaram a importância de se determinar essas frações. Segundo esses autores, o fracionamento de forma acurada permite a formulação de dietas nutricionalmente adequadas, o que possibilita, portanto, maximizar a eficiência de utilização da energia e do nitrogênio, tanto pelos microrganismos quanto pelo próprio animal. Além disso, pode permitir a redução das perdas energéticas e nitrogenadas decorrentes da fermentação ruminal (Russell et al., 1992).

A fração proteica dos alimentos pode ser fracionada em componentes A (fração solúvel nitrogênio não proteico, NNP), $B_{1}$ (fração solúvel rapidamente degradada no rúmen), $\mathrm{B}_{2}$ (fração insolúvel, com taxa de degradação intermediária no rúmen), $\mathrm{B}_{3}$ (fração insolúvel lentamente degradada no rúmen) e fração $\mathrm{C}$, que é indigestível durante sua permanência no trato gastrintestinal.

Os carboidratos podem ser fracionados em componentes A (açúcares solúveis com rápida degradação ruminal), $\mathrm{B}_{1}$ (amido e pectina), $\mathrm{B}_{2}$ (correspondente à fibra potencialmente degradável com taxa de degradação mais lenta) e C, que apresenta característica de indigestibilidade. Este subfracionamento foi descrito por Sniffen et al. (1992), como sendo objeto de entrada de dados para o sistema Cornell
Net Carbohydrate and Protein System (CNCPS). Este sistema tem o objetivo de estimar taxas de degradação ruminal de diferentes subfrações dos alimentos, maximizar a sincronização de proteína e carboidratos no rúmen, e consequentemente a produção microbiana e ainda minimizar as perdas nitrogenadas (Sniffen et al., 1992).

Como consequência das possíveis alterações na composição bromatológica da silagem de capim que um determinado aditivo pode proporcionar à determinação das frações de carboidratos e proteínas, bem como a degradação ruminal da matéria seca, proteína bruta e fibra em detergente neutro das silagens é de suma importância para avaliar as melhorias no valor nutritivo da silagem com a inclusão do aditivo. Adicionalmente, essas informações têm sido utilizadas nos sistemas mais modernos de adequação de dietas para ruminantes, no sentido de permitir a formulação de dietas que otimizem o desempenho animal, associadas às reduções da emissão de metano e perdas de nutrientes via fezes e urina (Tonani et al., 2001).

Carvalho et al. (2008) determinaram as frações que compõem as proteínas das silagens de capimelefante submetido ao emurchecimento ou à adição de $0,7,14,21$ e $28 \%$ de farelo de cacau. Os autores concluíram que as frações protéicas foram influenciadas pelas adições de farelo de cacau, verificando-se redução dos teores das frações $\mathrm{A}$ e $\mathrm{B}_{1}+\mathrm{B}_{2}$ e aumentos das frações $\mathrm{B}_{3}$ e $\mathrm{C}$, para os níveis crescentes de farelo de cacau.

No mesmo sentido, Pires et al. (2009) avaliaram as frações que compõem os carboidratos e as proteínas das silagens de capimelefante com $15 \%$ de casca de café, farelo de cacau ou farelo de mandioca. $\mathrm{O}$ maior teor de carboidratos totais foi observado na silagem com farelo de mandioca e o menor na silagem com farelo de cacau, seguida das silagens controle e com casca de café. Maiores valores de carboidratos não-fibrosos $\left(\mathrm{A}+\mathrm{B}_{1}\right)$ também foram verificados para as silagens com farelo de mandioca. Os menores valores de fração indigestível $(\mathrm{C}, \% \mathrm{CT})$ foram observados para a silagem com farelo de mandioca, enquanto as silagens com casca de café e farelo de cacau apresentaram os maiores valores desta fração. Os autores concluíram que o farelo de mandioca ensilado com capim-elefante é um bom aditivo para a produção de silagem.

Ao avaliarem a inclusão de 0, 10, 20 e 30\% de farelo de mandioca, casca de café ou farelo de 
cacau sobre o fracionamento de proteína e carboidratos da silagem de capim-elefante, Andrade et al. (2010a) concluíram que o farelo de mandioca contribuiu para redução do teor de nitrogênio insolúvel em detergente ácido, apresentando os maiores valores para a fração $\mathrm{A}$ da proteína e para os teores das frações $\mathrm{B}_{1}+\mathrm{B}_{2}$. Em contrapartida, o farelo de cacau proporcionou acréscimo da fração C, aumentando significativamente o teor de proteína indisponível para os microrganismos ruminais. $O$ farelo de mandioca aumenta o teor de carboidratos nãofibrosos da silagem, enquanto a casca de café e o farelo de cacau aumentam a fração não-digerível dos carboidratos.

Na premissa de avaliar a degradação ruminal da silagem de capim-elefante com diferentes componentes de algaroba (farelo, vagem e amido), Santos et al. (2012) encontraram maior degradabilidade na silagem com amido de algaroba. A algaroba e seus componentes constituem uma alternativa viável a ser adicionada na silagem de capim elefante. Contudo, de acordo com os autores, o amido de algaroba é mais eficiente.

\section{Considerações Finais}

A inclusão de farelo de arroz reduz a umidade e melhora a composição bromatológica da silagem de capim-braquiária. Adicionalmente, níveis elevados ultrapassam os valores de extrato etéreo preconizados para a manutenção dos microrganismos ruminais.

\section{Referências Bibliográficas}

Andrade, I. V. O., Pires, A. J. V., Carvalho, G. G. P., Veloso, C. M. \& Bonomo, P. 2010a. Fracionamento de proteína e carboidratos em silagens de capim-elefante contendo subprodutos agrícolas. Revista Brasileira de Zootecnia, 39.

Andrade, I. V. O., Pires, A. J. V., Carvalho, G. G. P., Veloso, C. M. \& Bonomo, P. 2010b. Perdas, características fermentativas e valor nutritivo da silagem de capim-elefante contendo subprodutos agrícolas. Revista Brasileira de Zootecnia, 39, 2578-2588.

Andrade, J. B. \& Lavezzo, W. 1998. Aditivos na ensilagem do capim-elefante. I. Composição bromatológica das forragens e das respectivas silagens. Pesquisa Agropecuária Brasileira, 33, 1859-1872.
Andriguetto, J. M., Perly, Y., L. \& Minardi, I. 2003. Nutrição Animal. Editora Nobel.

Bernardino, F. S., Garcia, R., Rocha, F. C., Souza, A. L. \& Pereira, O. G. 2005. Produção e características do efluente e composição bromatológica da silagem de capim-elefante contendo diferentes níveis de casca de café. Revista Brasileira de Zootecnia, 34, $2185-$ 2291.

Cabral, L. S., Valadares Filho, S. C., Malafaia, P. A. M., Lana, R. P., Silva, J. F. C., Vieira, R. A. M. \& Pereira, E. S. 2000. Frações protéicas de alimentos tropicais e suas taxas de digestão estimadas pela incubação com proteases ruminais. Revista Brasileira de Zootecnia, 29, 2316-2324.

Cabral, L. S., Valadares Filho, S. d. C., Detmann, E., Zervoudakis, J. T., Veloso, R. G. \& Nunes, P. M. M. 2004. Taxas de digestão das frações protéicas e de carboidratos para as silagens de milho e de capim-elefante, o feno de capimtifton-85 eo farelo de soja. Revista Brasileira de Zootecnia, 33, 1573-1580.

Carvalho, G., Garcia, R., Pires, A., Pereira, O., Fernandes, F. \& Carvalho, B. 2008. Características fermentativas de silagens de capim-elefante emurchecido ou com adição de farelo de cacau. Arquivo Brasileiro de Medicina Veterinaria e Zootecnia, 60, 234242.

Chiarelli, C.A., Ruggieri, A.C., Cunha Neto, D.C., Janusckiewicz, E.R., Santos, N.L. 2009. Interferências entre a cultura do milho e três cultivares de Brachiaria brizantha em consórcio. Congresso de Iniciação Científica da Unesp. São José do Rio Preto, São Paulo.

Clipes, R. C., Detmann, E., Silva, J. F. C., Vieira, R. A. M., Nunes, L. B. M., Lista, F. N. \& Ponciano, N. J. 2006. Evaluation of acid detergent insoluble protein as an estimator of rumen non-degradable protein in tropical grass forages. Arquivo Brasileiro de Medicina Veterinária e Zootecnia, 58, 694-697.

Euclides, V. P. B., Valle, C. B., Macedo, M. C. M. \& Oliveira, M. P. 2001. Evaluation of Brachiaria brizantha ecotypes under grazing in small plots. International Grassland Congress. São Paulo, Brasil.

Fagundes, J. L., Fonseca, D. M., Gomide, J. A., Nascimento Junior, D., Vitor, C. M. T., Morais, R. V., Mistura, C., Gilberto, C. R. \& Martuscello, J. A. 2005. Acúmulo de forragem em pastos de Brachiaria decumbens adubados 
com nitrogênio. Pesquisa Agropecuária Brasileira, 40, 397-403.

Ferrari Junior, E., Paulino, V. T., Possenti, R. A. \& Lucenas, T. L. 2009. Aditivos em silagem de capim Elefante Paraíso (Pennisetum hybridum cv. Paraíso). Archivos de Zootecnia, 58, 185194.

Igarasi, M. S. 2002. Controle de perdas na ensilagem de capim Tanzânia (Panicum maximum Jacq. cv. Tanzânia) sob os efeitos do teor de matéria seca, do tamanho de partícula, da estação do ano e da presença do inoculante bacteriano. Universidade de São Paulo, Piracicaba.

Ítavo, L. C. V., Valadares Filho, S. d. C., Silva, F. F., Valadares, R. F. D., Cecon, P. R., Ítavo, C. C. B. F., Moraes, E. H. B. K. \& Paulino, P. V. R. 2002. Consumo, degradabilidade ruminal e digestibilidade aparente de fenos de gramíneas do gênero Cynodon e rações concentradas utilizando indicadores internos. Revista Brasileira de Zootecnia, 31, 1024-1032.

Martuscello, J. A., Fonseca, D., Nascimento Júnior, D., Santos, P., Ribeiro Júnior, J., Cunha, D. \& Moreira, L. d. M. 2005. Características morfogênicas e estruturais do capim-xaraés submetido à adubação nitrogenada e desfolhação. Revista Brasileira de Zootecnia, 34, 1475-1482.

McDonald, P. 1981. The biochemistry of silage. John Wiley \& Sons, Ltd., Oklahoma: Marlow.

Mertens, D. R. 1993. Rate and extent of digestion. In: Forbes, J. M. \& France, J. (eds.) Quantitative aspects of ruminant digestion and metabolism. CAB Publishing, Wallingford.

Molina, L. R., Rodriguez, N. M., Gonçalves, L. C., Borges, I. \& Sousa, B. M. 2003. Effect of tannin on in situ degradability of the dry matter and crude protein of six sorghum silage genotypes (Sorghum bicolor (L.) Moench), harvested at dough stage. Arquivo Brasileiro de Medicina Veterinária e Zootecnia, 55, 203208.

Monteiro, I. J. G., Abreu, J. G., Silva Cabral, L., Ribeiro, M. D. \& dos Reis, R. H. P. 2011. Silagem de capim-elefante aditivada com produtos alternativos. Acta Scientiarum. Animal Sciences, 33, 347-352.

Nocek, J. E. 1988. In situ and other methods to estimate ruminal protein and energy digestibility: a review. Journal of Dairy Science, 71, 2051-2069.
Ørskov, E. R. \& McDonald, I. 1979. The estimation of protein degradability in the rumen from incubation measurements weighted according to rate of passage. The Journal of Agricultural Science, 92, 499-503.

Pires, A. J. V., Carvalho, G. G. P., Garcia, R., Carvalho Júnior, J. N., Ribeiro, L. S. O. \& Chagas, D. M. T. 2009. Fracionamento de carboidratos e proteínas de silagens de capimelefante com casca de café, farelo de cacau ou farelo de mandioca. Revista Brasileira de Zootecnia, 38, 422-427.

Russell, J. B., O'connor, J. D., Fox, D. G., Van Soest, P. J. \& Sniffen, C. J. 1992. A net carbohydrate and protein system for evaluating cattle diets: I. Ruminal fermentation. Journal of Animal Science, 70, 3551-3561.

Santos, S., Santos-Cruz, C. L. d., Rocha, J. B., Pires, A. J. V., Santos, Í. P. A., Lima, T. R. \& Junqueira, R. S. 2012. Degradação ruminal da silagem de capim elefante com diferentes componentes de algaroba. Revista Brasileira de Saúde e Produção Animal, 13, 123-136.

Sniffen, C. J., O'Connor, J. D., Van Soest, P. J., Fox, D. G. \& Russell, J. B. 1992. A net carbohydrate and protein system for evaluating cattle diets: II. Carbohydrate and protein availability. Journal of Animal Science, 70, 3562-77.

Souza Filho, A. B. S. F. \& Dutra, S. 1991. Resposta do Brachiaria humidicola à adubação em campo cerrado do estado do Amapá, Brasil. Pasturas Tropicales, 13, 42-45.

Souza, F.H.D. As sementes de espécies forrageiras do gênero Brachiaria no Brasil Central. Brachiaria no novo século. 2.ed. Nova Odessa: Instituto de Zootecnia, 2002.

Tonani, F. L., Ruggieri, A. C., Queiroz, A. C. \& Andrade, P. 2001. Degradabilidade ruminal in situ da matéria seca e da fibra em detergente neutro em silagens de híbridos de sorgo colhidos em diferentes épocas Ruminal in situ degradability of dry matter and neutral detergent fiber of sorghum (Sorghum bicolor L.) silages with different harversting times. Arquivo Brasileiro de Medicina Veterinária e Zootecnia, 53, 100-104.

Zanine, A. M., Santos, E. M., Dórea, J. R. R., Dantas, P. A. S., Silva, T. C. \& Pereira, O. G. 2010. Evaluation of elephant grass silage with the addition of cassava scrapings. Revista Brasileira de Zootecnia, 39, 2611-2616. 
Zanine, A. M., Santos, E. M., Ferreira, D. J., Oliveira, J. S. \& Pereira, O. G. 2006a. Avaliação da silagem de capim-elefante com adição de farelo de trigo. Archivos de Zootecnia, 55, 75-84.

Zanine, A. M., Santos, E. M., Jesus Ferreira, D., Pereira, O. G. \& Almeida, J. C. C. 2006b. Efeito do farelo de trigo sobre as perdas, recuperação da matéria seca e composição bromatológica de silagem de capim-mombaça.
Brazilian Journal of Veterinary Research and Animal Science, 43, 803-809.

Article History:

Received 4 October 2017

Accepted 27 October 2017

Available online 10 January 2018

License information: This is an open-access article distributed under the terms of the Creative Commons Attribution License 4.0, which permits unrestricted use, distribution, and reproduction in any medium, provided the original work is properly cited. 